\title{
Did the COVID-19 Pandemic Truly Adversely Affected the Disease Progress and Therapeutic Options in Breast Cancer Patients? - a Single-centre Analysis
}

\section{Tomasz Nowikiewicz ( $\nabla$ tomasz.nowikiewicz@cm.umk.pl)}

Nicolaus Copernicus University in Toruń Ludwik Rydygier Collegium Medicum in Bydgoszcz:

Uniwersytet Mikolaja Kopernika w Toruniu Collegium Medicum im Ludwika Rydygiera w Bydgoszczy https://orcid.org/0000-0002-6492-4427

\section{Maria Szymankiewicz}

Oncology Center-Prof. F. Lukaszczyk Memorial Hospital

\section{Marta Drzewiecka}

Oncology Center-prof. F. Lukaszczyk Memorial Hospital

\section{Iwona Glowacka-Mrotek}

Nicolaus Copernicus University in Toruń Ludwik Rydygier Collegium Medicum in Bydgoszcz:

Uniwersytet Mikolaja Kopernika w Toruniu Collegium Medicum im Ludwika Rydygiera w Bydgoszczy

\section{Magdalena Tarkowska}

Nicolaus Copernicus University in Toruń Ludwik Rydygier Collegium Medicum in Bydgoszcz:

Uniwersytet Mikolaja Kopernika w Toruniu Collegium Medicum im Ludwika Rydygiera w Bydgoszczy

\section{Magdalena Nowikiewicz}

Nicolaus Copernicus University in Toruń Ludwik Rydygier Collegium Medicum in Bydgoszcz:

Uniwersytet Mikolaja Kopernika w Toruniu Collegium Medicum im Ludwika Rydygiera w Bydgoszczy

\section{Wojciech Zegarski}

Nicolaus Copernicus University in Toruń Ludwik Rydygier Collegium Medicum in Bydgoszcz:

Uniwersytet Mikolaja Kopernika w Toruniu Collegium Medicum im Ludwika Rydygiera w Bydgoszczy

\section{Research Article}

Keywords: breast cancer, diagnostic and treatment, COVID-19 pandemic, cohort study

Posted Date: September 3rd, 2021

DOl: https://doi.org/10.21203/rs.3.rs-840639/v1

License: (a) (1) This work is licensed under a Creative Commons Attribution 4.0 International License. Read Full License 
Page 2/11 


\section{Abstract}

Purpose The mass and uncontrolled spreading of infections with the SARS-CoV-2 virus resulted in significant disruptions affecting most areas of the social and economic life all over the world. The most important changes concerned problems related to functioning of health care systems. The aim of this study was to evaluate clinical consequences associated with the COVID-19 pandemic for patients with newly diagnosed breast cancer, treated at our centre.

Methods The study participants were patients first time diagnosed with breast cancer, treated between January 2019 and March 2021, who were provided any type of cancer treatment at our centre. The study determined the grade of clinical and pathological progress of the disease and types of cancer treatment applied in patients.

Results 2863 patients in total were included in the analysis. The number of hospitalised patients was 1228 (1123 treated surgically, 105 receiving conservative treatment) in 2019, 1318 (1206 and 112 patients, respectively) in 2020, and 317 (288 and 29 patients, respectively) in 2021.

Conclusions Despite many hazards associated with the new epidemiological situation, we were able to maintain the continuous operation of our centre. We have achieved a measurable success, and even managed to increase the number of treated breast cancer patients.

\section{Introduction}

On March 11, 2021, one year passed since the World Health Organization announced the global COVID-19 pandemic [1]. The mass and uncontrolled spreading of infections with the SARS-CoV-2 virus resulted in significant disruptions affecting most areas of the social and economic life all over the world. The most important changes concerned problems related to functioning of health care systems, which relatively quickly became overloaded, and in some cases, ineffective, at least in certain areas [2]. Furthermore, the new epidemiological situation negatively affected possibilities for diagnosing and initiating treatment in patients with other diseases. This became particularly significant in the case of malignant neoplasms. The observed delays concerned both the early diagnosis of cases, as well as diagnostic and therapeutic activities [3-5].

A number of actions were undertaken in response to this new situation. For example, recommendations of scientific associations concerning management of the cancer treatment were modified [6, 7]. A continuous monitoring of current consequences of the pandemic was introduced, including evaluation of their influence on this group of patients [8, 9].

The aim of this study was to evaluate clinical consequences associated with the COVID-19 pandemic for patients with newly diagnosed breast cancer, treated at our centre.

\section{Material And Methods}




\section{Patient group}

The study participants were patients first time diagnosed with breast cancer (diagnoses from groups C50 and D05 according to ICD-10), treated between Jan 2019 and March 2021, who were provided any type of cancer treatment at our centre. The study was approved by the Ethics Committee at the Nicholas Copernicus University in Toruń, Collegium Medicum in Bydgoszcz (KB 312/2021 of May 18, 2021). Due to the retrospective character of the analysis, patient written consents to participation in the study were not required under the decision of the Ethics Committee.

Taking into account the moment, in which restrictions related to the COVID-19 pandemic were introduced, the analysed period was divided into two stages: Jan 2019-March 2020 - before the pandemic (group I) and April 2020-March 2021 - after its announcement (group II).

Treatment plans for patients were established in accordance with the generally applicable standards of therapeutic management for breast cancer [10,11].

\section{Evaluated clinical data}

Clinical data required for the analysis came from a prospectively maintained database and from patients' medical hospital records.

The study determined: 1 . a grade of clinical and pathological progress of the disease [12], 2. types of cancer treatment applied in patients.

Statistical analysis was conducted using IBM SPSS Statistics 27 data analysis software. Between-groups differences were assessed using t-Student test for continuous variables and chi-square test ( $\mathrm{HO}$ Wald statistics) for categorical variables. Data are presented as a mean \pm standard deviation or a number of cases and percentage where appropriate. In all statistical analyses the cut-off value for probability coefficient was set at $p$ value $\leq 0.05$.

\section{Results}

2863 patients in total were included in the analysis. The number of hospitalised patients was 1228 (1123 treated surgically, 105 receiving conservative treatment) in 2019, 1318 (1206 and 112 patients, respectively) in 2020, and 317 (288 and 29 patients, respectively) between Jan and March, 2021. The detailed clinical data of patients qualified for surgical treatment is shown in Table 1. 
Table 1

Clinical characteristics of patients qualified for the study (patients after surgical treatment).

\begin{tabular}{|c|c|c|c|}
\hline \multirow[t]{2}{*}{ Clinical data analysed } & $\begin{array}{l}\text { Group I } \\
\text { (pre-pandemic } \\
\text { period) }\end{array}$ & $\begin{array}{l}\text { Group II } \\
\text { (pandemic } \\
\text { period) }\end{array}$ & $\mathrm{p}$ \\
\hline & $n=1355$ & $n=1262$ & \\
\hline Age (range) & $59.2 \pm 12.2(27-91)$ & $\begin{array}{l}58.8 \pm 12.3(24- \\
90)\end{array}$ & 0.392 \\
\hline Histological form of cancer: & & & 0.369 \\
\hline -invasive & $1261(93.1)$ & $1189(94.2)$ & \\
\hline -preinvasive (DCIS, LCIS) & $94(6.9)$ & $73(5.8)$ & \\
\hline Palpability of a tumour & $891(65.9)$ & $924(73.3)$ & $<0.001$ \\
\hline Tumour size - clinical evaluation [mm] (range) & $26.0 \pm 18.9(5-200)$ & $\begin{array}{l}27.3 \pm 19.0(4- \\
150)\end{array}$ & 0.033 \\
\hline \multicolumn{4}{|l|}{ Tumour size - clinical evaluation: } \\
\hline \multicolumn{4}{|l|}{-ст0 } \\
\hline -cT1 & $2(0.2)$ & 0 & 0.172 \\
\hline -сT2 & $662(48.9)$ & $528(41.8)$ & $<0.001$ \\
\hline -cT3 & $528(39.0)$ & $565(44.8)$ & 0.003 \\
\hline \multirow[t]{2}{*}{-cT4 } & $78(5.8)$ & $100(7.9)$ & 0.028 \\
\hline & $82(6.1)$ & $66(5.2)$ & 0.363 \\
\hline \multirow{2}{*}{\multicolumn{4}{|c|}{$\begin{array}{l}\text { Metastatic lesions - clinical evaluation: } \\
\text {-cNO }\end{array}$}} \\
\hline & & & \\
\hline$-\mathrm{cN} 1$ & 1119 (82.6) & $1043(82.6)$ & 0.966 \\
\hline$-\mathrm{cN} 2$ & $204(15.1)$ & $194(15.4)$ & 0.821 \\
\hline \multirow[t]{2}{*}{$-\mathrm{cN3}$} & $24(1.8)$ & $21(1.7)$ & 0.833 \\
\hline & $8(0.6)$ & $4(0.3)$ & 0.301 \\
\hline \multicolumn{4}{|l|}{ Clinical stage (cTNM): } \\
\hline$-I(I A)$ & $621(45.8)$ & $505(40.0)$ & 0.003 \\
\hline - II: & $610(45.0)$ & 647 (51.3) & 0.001 \\
\hline$\| \mathrm{A}$ & $453(33.4)$ & $469(37.2)$ & 0.046 \\
\hline II B & $157(11.6)$ & $178(14.1)$ & 0.054 \\
\hline
\end{tabular}




\begin{tabular}{|c|c|c|c|}
\hline - III: & 116 (8.6) & $103(8.2)$ & 0.713 \\
\hline III A & $34(2.5)$ & $41(3.3)$ & 0.257 \\
\hline III B & $75(5.5)$ & $59(4.7)$ & 0.319 \\
\hline III C & $7(0.5)$ & $3(0.2)$ & 0.248 \\
\hline - IV & $8(0.6)$ & $7(0.6)$ & 0.904 \\
\hline $\begin{array}{l}\text { Tumour size - pathological evaluation: } \\
\text {-pT0 }\end{array}$ & $N=1006$ & $N=911$ & \\
\hline -pTis & $1(0.1)$ & 0 & 0.341 \\
\hline -pT1 & $94(9.3)$ & $73(8.0)$ & 0.302 \\
\hline pT1mic & $510(50.7)$ & $460(50.5)$ & 0.930 \\
\hline pT1a & $16(1.6)$ & 27 (3.0) & 0.043 \\
\hline pT1b & $53(5.3)$ & $36(4.0)$ & 0.171 \\
\hline pT1c & $149(14.8)$ & $113(12.4)$ & 0.126 \\
\hline -рT2 & $292(29.0)$ & 284 (31.2) & 0.306 \\
\hline -pT3 & $370(36.8)$ & $341(37.4)$ & 0.768 \\
\hline \multirow[t]{2}{*}{-pT4 } & $13(1.3)$ & $25(2.7)$ & 0.023 \\
\hline & $18(1.8)$ & $12(1.3)$ & 0.406 \\
\hline $\begin{array}{l}\text { Tumour size - pathological evaluation [mm] } \\
\text { (range) }\end{array}$ & $20.2 \pm 19.0(1-260)$ & $\begin{array}{l}21.1 \pm 14.4(1- \\
110)\end{array}$ & 0.048 \\
\hline \multicolumn{4}{|l|}{$\begin{array}{l}\text { Metastatic lesions - pathological evaluation: } \\
\text {-pN0 }\end{array}$} \\
\hline -pN1mi & $651(64.7)$ & $622(68.3)$ & 0.099 \\
\hline$-p N 1 a$ & $24(2.4)$ & $19(2.1)$ & 0.658 \\
\hline$-p N 2 a$ & $161(16.0)$ & $145(15.9)$ & 0.958 \\
\hline$-p N 3 a$ & $60(6.0)$ & $38(4.2)$ & 0.075 \\
\hline \multirow[t]{2}{*}{$-p N x$} & $37(3.7)$ & $28(3.1)$ & 0.465 \\
\hline & $73(7.3)$ & $59(6.5)$ & 0.501 \\
\hline Neoadjuvant treatment & $349(25.8)$ & 351 (27.8) & 0.235 \\
\hline BCT & 890 (65.7) & 760 (60.2) & 0.004 \\
\hline Mastectomy & 465 (34.3) & $502(39.8)$ & \\
\hline ACT & 913 (67.4) & 850 (67.4) & 0.988 \\
\hline
\end{tabular}


Tumour diagnosed during screening mammography

Patient place of residence (voivodeship):

-Kujawsko-Pomorskie

- other

1138 (84.0)

$217(16.0)$
1051 (83.3)

$211(16.7)$

Out of the total number of patients, $9.1 \%(135 / 1490)$ and $8.1 \%(111 / 1373)$ were qualified for the conservative treatment at the first and the second stage of the study, respectively. Surgical treatment was mainly impossible because of a diagnosis of cancer spread. Distant metastases were diagnosed in $58.5 \%(79 / 135)$ and $69.4 \%(77 / 111)$ patients from group I and group II, respectively. This concerned $57.1 \%(60 / 105), 62.5 \%(70 / 112)$ and $89.7 \%(26 / 29)$ of patients provided conservative treatment in 2019, 2020 , and 2021, respectively. In the remaining cases, conservative treatment was a consequence of not giving consent to surgical treatment or a generally poor condition of patients, breast cancer progress during the inductive systemic treatment or second cancer in a different site.

\section{Discussion}

Although the presented data comes from only one centre of oncology, yet it may be treated as representative for the whole Poland. It reflects the situation at the centre treating the largest number of patients with newly diagnosed breast cancer every year. Furthermore, the Kujawsko-Pomorskie Voivodeship, in which the Centre of Oncology in Bydgoszcz operates, is a typical industrial and agricultural region of the country, with a number of inhabitants ( 2.07 million), a population density (116 people $\left./ \mathrm{km}^{2}\right)$ and a percentage of urban areas $(61.1 \%)$ at an average level.

Contrary to data indicating a decreasing number of cancer patients coming to oncology centres [3-5], the situation found at our centre was different. When compared to the situation before the pandemic, $15.6 \%$ more patients qualified for surgical treatment were hospitalised at the second stage of the study (when comparing 12-month periods: April 2019-March 2020 and April 2020-March 2021, 1092 and 1262 patients, respectively). At the same time, the number of patients receiving the conservative treatment did not change (110 and 111 patients, respectively, in the same 12-month periods). However, in that case the number of patients receiving the palliative treatment increased.

Different data was presented by Gathani et al. [13], who found that the number of patients starting treatment for breast cancer in the first six months of 2020 was lower by $16 \%$ versus the corresponding period in 2019. A similar decreasing trend was observed by Baxter et al., who described a nearly $20 \%$ reduction in the number of patients receiving the systemic treatment, observed during first 4 months of 
the pandemic [4]. The changes described above also apply to the number of patients with other cancers $[4,14-16]$. So, did we manage to achieve something impossible in our case?

Despite many hazards associated with the new epidemiological situation, we maintained the continuous operation of our centre. This was possible due to introduction of a number of restrictions (for example, an access to inpatient wards was completely forbidden to any third persons, significant restrictions in that respect were also implemented at outpatient clinics, hospitalised people were required to remain in their room at all times, and our personnel had restricted possibilities of working outside our centre) and additional requirements (e.g., all patients were tested for the SARS-CoV-2 infection before starting each hospitalisation, a change in a system for meals distribution - meals were again delivered to hospital rooms, replacing the generally accessible hospital restaurant, duration of patient hospitalisation was reduced to a necessary minimum), as well as a fast restart of the programme for early breast cancer diagnosis (mammographic screening). The listed actions were definitely also used in other health care centres. However, in our case they proved to be highly effective.

In the studied group of patients, the most important consequence of the COVID-19 pandemic is a higher clinical staging of newly diagnosed neoplasms. The resulting differences (highly statistically significant: stage $I-p=0.003$, stage $I I-p=0.001$ ) are a consequence of a progress in the primary tumour size observed during the pandemic (in a clinical: $p=0.033$ and pathological: $p=0.048$ evaluation). At the same time, they did not result from a change of the most important prognostic factor in breast cancer patients - the axillary lymph node status [17] (no significant difference in that respect was found in both compared groups).

The increase in the percentage of mastectomies (by $5.5 \%-p=0.004$ ) during the pandemic stage did not result from a change in a way in which patients were qualified for this surgery. It also did not result from a reduction in the use of auxiliary radiotherapy (associated with the breast-conserving therapy) by the patients or by the therapeutic team. However, it was closely related to the said change in the primary tumour size.

An increase in the overall number of breast cancer cases treated at our centre during the pandemic stage did not result from the introduction of any changes in the distribution of cancer patients at a national level. However, it was possible due to implementation of strict management protocols concerning organisation of diagnostics and patient treatment. However, in our opinion, we cannot stop only at initiatives undertaken at a bottom level, even those most proven and effective. We believe that a systemic intensification of all efforts that may prevent delays in diagnosing and treatment of cancer patients is necessary. From our national perspective, such actions were not undertaken in the greatest extent. We should never again leave cancer patients on their own, even if for a short time.

The currently continuing COVID-19 pandemic has clearly changed the health situation of societies all over the world. With the improvement in the pandemic situation (mainly, due to widespread vaccinations against SARS-CoV-2), the actions aiming at restoring all solutions for organisation and treatment of neoplastic diseases in force before the pandemic should be undertaken as soon as possible. However, the 
questions about the length of a period required to return to the initial situation, as well as about the pandemic influence on delayed treatment outcomes still remain open [18].

\section{Abbreviations}

ACT - axillary conserving treatment; ALND - axillary lymph node dissection; BCT - breast conserving treatment; DCIS - ductal carcinoma in situ; LCIS - lobular carcinoma in situ; P - P value; cT/pT clinical/pathological size of primary tumor

\section{Declarations}

\section{Author Contributions}

All authors contributed to the study concept and design. Material preparation, data collection, and analysis were performed by Tomasz Nowikiewicz, Maria Szymankiewicz, Marta Drzewiecka, Iwona Głowacka-Mrotek, Magdalena Tarkowska, Magdalena Nowikiewicz and Wojciech Zegarski. The first draft of the manuscript was written by Tomasz Nowikiewicz and all authors commented on previous versions of the manuscript. All authors read and approved the final manuscript.

\section{Data availability}

The datasets generated and analyzed during the current study are available from the corresponding author on reasonable request.

\section{Compliance with ethical standards}

\section{Funding}

This study was funded in part by the statutory activity no. 737-2019 (Ludwik Rydygier's Collegium Medicum in Bydgoszcz, Nicolaus Copernicus University in Torun).

\section{Conflict of interest statement}

The authors have no conflicts of interest to disclose.

\section{Ethical approval}

This retrospective chart review study involving human participants was in accordance with the ethical standards of the institutional and national research committee and with the 1964 Helsinki Declaration and its later amendments or comparable ethical standards. This article does not contain any studies with animals performer by any of the authors.

The study was approved by the Ethics Committee at the Nicholas Copernicus University in Toruń, Collegium Medicum in Bydgoszcz (KB 312/2021 of May 18, 2021). 


\section{References}

1. Cucinotta D, Vanelli M (2020) WHO Declares COVID-19 a Pandemic. Acta Biomed 91(1),157-160. DOI: https://doi.org/10.23750/abm.v91i1.9397

2. Barclay ME, Abel GA, Greenberg DC et al (2021) Sociodemographic variation in stage at diagnosis of breast, bladder, colon, endometrial, lung, melanoma, prostate, rectal, renal and ovarian cancer in England and its population impact. Br J Cancer 124(7),1320- DOI: 10.1038/s41416-021-01279-z

3. Sud A, Torr B, Jones ME et al (2020) Effect of delays in the 2-week-wait cancer referral pathway during the COVID-19 pandemic on cancer survival in the UK: a modelling study. Lancet Oncol 21(8),1035-1044. DOI: 1016/S1470-2045(20)30392-2

4. Baxter MA, Murphy J, Cameron D et al (2021) The impact of COVID-19 on systemic anticancer treatment delivery in Scotland. Br J Cancer 124(8),1353-1356. DOI: 1038/s41416-021-01262-8

5. Lai AG, Pasea L, Banerjee A et al (2020) Estimated impact of the COVID-19 pandemic on cancer services and excess 1 -year mortality in people with cancer and multimorbidity: near real-time data on cancer care, cancer deaths and a population-based cohort study. BMJ Open 10(11),e043828. DOI: 1136/bmjopen-2020-043828

6. Xu W, Piper-Vallillo AJ, Bindal P et al (2021) Time to SARS-CoV-2 clearance among patients with cancer and COVID-19. Cancer Med 10(5),1545-DOI: 10.1002/cam4.3708

7. Gradishar WJ, Moran MS, Abraham J et al (2021) NCCN Guidelines Insights: Breast Cancer, Version 4.2021. J Natl Compr Canc Netw 19(5),484-DOI: 10.6004/jnccn.2021.0023

8. Anil I, Arnold R, Benkwitz-Beford S et al (2020) The UK Coronavirus Cancer Monitoring Project: protecting patients with cancer In the era of COVID-19. Lancet Oncol 21(5),622-624. DOI: 1016/S1470-2045(20)30230-8

9. Kuderer NM, Choueiri TK, Shah DP et al (2020) Clinical impact of COVID-19 on patients with cancer (CCC19): a cohort study. Lancet 395(10241),1907-1918. DOI: 1016/S0140-6736(20) $\underline{31187-9}$

10. Curigliano G, Burstein HJ, Winer EP et al (2017) De-escalating and escalating treatments for earlystage breast cancer: the St. Gallen International Expert Consensus Conference on the Primary Therapy of Early Breast Cancer 2017. Ann Oncol 28(8):1700-1712. DOI: 1093/annonc/mdx806

11. Network NCC. NCCN Clinical Practice Guidelines in Oncology. Breast Cancer Version 4. 2021. Available online: https://www.nccn.org/professionals/physician_gls/ pdf/breast.pdf (accessed April $24,2021)$

12. Giuliano AE, Edge SB, Hortobagyi GN (2018) Eighth Edition of the AJCC Cancer Staging Manual: Breast Cancer. Ann Surg Oncol 25(7),1783-1785. DOI: 1245/s10434-018-6486-6

13. Gathani T, Clayton G, Maclnnes E et al (2021) The COVID-19 pandemic and impact on breast cancer diagnoses: what happened in England in the first half of 2020. Br J Cancer 124(4),710-712. DOI: 1038/s41416-020-01182-z

14. Wang $\mathrm{H}$, Elsheikh M, Gilmour $\mathrm{K}$ et al (2021) Impact of COVID-19 pandemic on eye cancer care in United Kingdom. Br J Cancer 12(8),1357- DOI: 10.1038/s41416-021-01274-4 
15. Zapala P, Slusarczyk A, Rajwa P et al (2021) Not as black as it is painted? The impact of the first wave of COVID-19 pandemic on surgical treatment of urological cancer patients in Poland - a crosscountry experience. Arch Med Sci. DOI: https://doi.org/10.5114/aoms/130927

16. Rutter MD, Brookes M, Lee TJ et al (2021) Impact of the COVID-19 pandemic on UK endoscopic activity and cancer detection: a National Endoscopy Database Analysis. Gut 70(3),537-DOI: 10.1136/gutjnl-2020-322179

17. Drinka E, Allen P, McBride A et al (2015) Metastatic tumor volume and extranodal tumor extension: clinical significance in patients with stage II breast cancer. Arch Pathol Lab Med 139(10),1288-1294. DOI: $\underline{5858 / a r p a .2014-0375-0 A}$

18. McCormack V, Aggarwal A (2021) Early cancer diagnosis: reaching targets across whole populations amidst setbacks. Br J Cancer 124(7),1181-1182. DOI: 1038/s41416-021-01276-2 